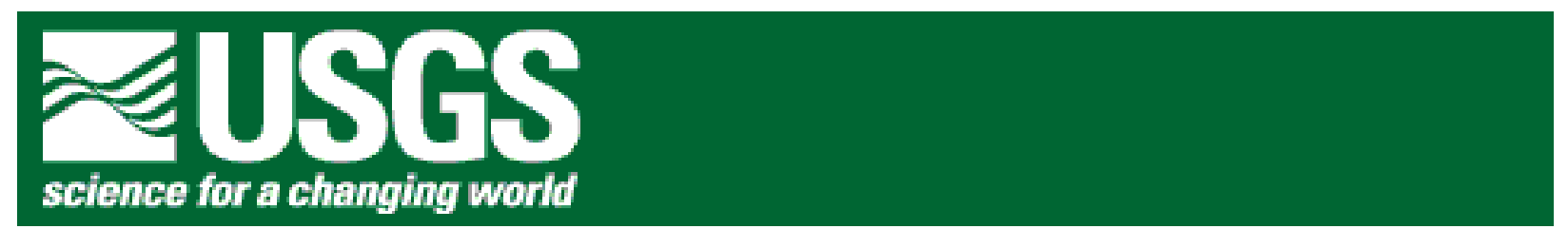

\title{
Calibration Formulae and Values for Velocity Seismometers Used in the 1998 Santa Clara Valley, California Seismic Experiment
}

by

Allan G. Lindh ${ }^{1}$

Jerry P. Eaton ${ }^{2}$

Mary O'Neill Allen ${ }^{2}$

John H. Healy ${ }^{2}$

Samuel W. Stewart ${ }^{2}$ and

Lu Damerell ${ }^{1}$

Open-File Report 99-434

1999

This report is preliminary and has not been reviewed for conformity with U.S. Geological Survey editorial standards or with the North American Stratigraphic Code. Any use of trade, firm, or product names is for descriptive purposes only and does not imply endorsement by the U.S. Government.

U.S. DEPARTMENT OF THE INTERIOR

U.S. GEOLOGICAL SURVEY

${ }^{1}$ Menlo Park, CA

${ }^{2}$ Retired 
Eaton (1975), Bakun and Dratler (1976), Eaton (1977), Healy and O’Neil (1977), Asten (1977), Stewart and O'Neill (1980), Liu and Peselnick (1986), Eaton (1991), Rodgers et al. (1995), and many others (see Asten (1977) for a list of earlier references) have presented formulae for calculating the damped generator constant (or motor constant), and the damping constant (or fractional damping ratio) for magnetically damped velocity seismometers.

Unfortunately the notation varies between authors, and not all the formulae allow for some of the significant variables -- differences in input impedance of the recording system in particular. This has become particularly relevant because the USGS seismic networks in California have traditionally set up their velocity sensors for the 10K Ohm impedance of the standard USGS analog telemetry systems (Eaton, 1977), but modern digital recording systems are usually set up with high input impedances, often of a megaohm or greater. Thus the nominal calibration values valid for USGS velocity sensors in their "normal” configuration are incorrect when they are recorded on other systems.

In this short note we have collected the relevant formulae needed, and computed the seismometer responses for the various velocity sensors used in the recent Santa Clara Valley Seismic Experiment (SCVSE, see Lindh et al., 1999).

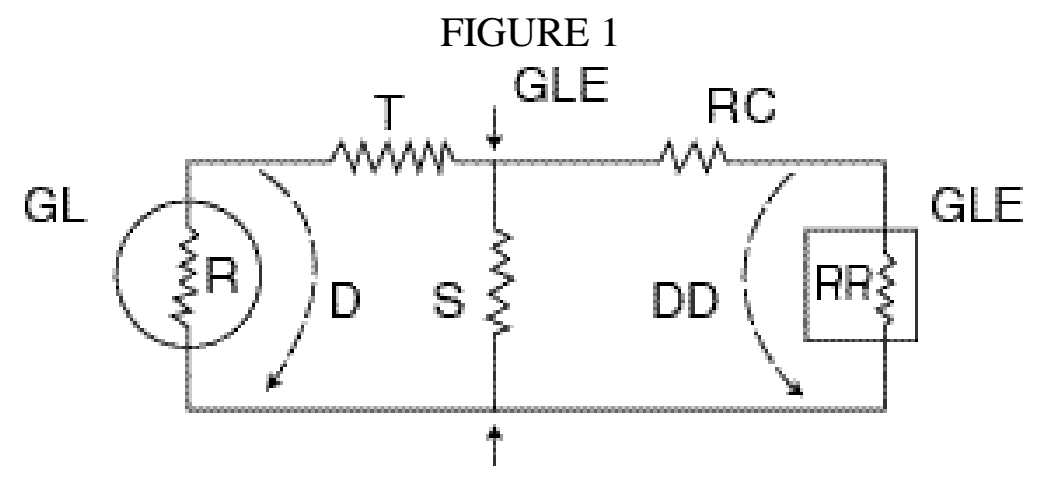

For simplicity we have used the notation of Eaton (1991), which is illustrated in Figure 1.

$R \quad$ Coil resistance of the seismometer (Ohms)

$T_{0} \quad$ The free period of the seismometer (sec)

$M \quad$ The seismometer mass (Kgms)

$\beta_{0} \quad$ Open circuit damping (\% of critical)

GL The undamped generator constant (v/m/s)

$S \quad$ Parallel (or shunt or damping) resistor used to modify the damping (Ohms)

$T \quad$ Series resistor used to modify the level of the damped generator constant (Ohms)

$\varpi_{0} \quad$ The natural frequency of the seismometer in radians $\left(\frac{2 \pi}{T_{0}}\right)$

$R R \quad$ The input impedance of the recording device (Ohms)

$\beta_{1} \quad$ Damping due to coil currents (\% of critical)

$\beta \quad$ Damping constant $\left(\beta_{0}+\beta_{1}\right)$ (\% of critical)

GLE The adjusted generator constant (v/m/s)

$R C$ The cable resistance, which is here taken to be 0 
Given these definitions, there are three cases we will consider here. The first is that we have all the required parameters for a given sensor (i.e. $R, T_{0}, M, \beta_{0}, G L, S, T$, and $R R$ ), and wish to recompute the damped generator constant and damping ratio ( $G L E$ and $\beta$ ), because of a change in one of the values -- the recording system input impedance, for instance. The second is that we have calibrated (or recalibrated) a seismometer, and wish to compute the values of the $S$ and $T$ resistors required to obtain a given level of output and damping. The third is that no series resistor is used $(T=0)$, and a value of $S$ is computed to produce the desired damping level; this effectively maximizes the output level for a given damping.

It should be noted that all the calibration values listed here are "lab values", and either come from the manufacturer ( $M$ in all cases, $G L, \beta_{0}$ and $T_{0}$ in some), or were measured in the lab by the USGS. The procedures used by the USGS for laboratory calibrations are described in Eaton (1991). We have not yet used calibration pulses recorded in the field during the SCVSE to check and/or update these values, but hope to complete that work at some point in the future.

\section{Scenario I: Determine GLE and $\beta$, given seismometer constants and external resistances.}

In Eaton (1975) and Healy and O'Neil (1977) one can find the required formulas, and with a bit of rearrangement obtain,

$$
G L E=\frac{G L}{R+D} \frac{S^{*} R R}{S+R R}
$$

and

$$
\beta_{1}=\frac{(G L)^{2}}{2 M \varpi_{0}(R+D)}
$$

where $D$, the external resistance, is

$$
D=T+\frac{S^{*} R R}{S+R R}
$$

and the common factor $(R+D)$ is simply the total resistance, seen from the seismometer's side of the circuit.

\section{Scenario II: Determine $S$ and $T$, given seismometer constants, input impedance, and desired outputs.}

From Healy and O'Neil (1977) one can obtain an expression for the external resistance $D$, in terms of the physical constants for the seismometer,

$$
D=\frac{(G L)^{2}}{2 \beta_{1} \varpi_{0} M}-R,
$$


where $\beta_{1}=\beta-\beta_{0}$.

Then from Eaton (1975) one can get the expression for the shunt resistor,

$$
S=\frac{F^{*} R R^{*}(R+D)}{R R-F^{*}(R+D)},
$$

where $F=\frac{G L E}{G L}$.

The required series resistance $T$ can then be obtained from formula (3) above

$$
T=D-\frac{S^{*} R R}{S+R R}
$$

\section{Scenario III: Determine $S$, given seismometer constants, input impedance, and desired damping ratio with $T=0$.}

Determine D from formula (4) above, and then equate to formula (3), set $T=0$, and rearrange terms to obtain,

$$
S=\frac{D^{*} R R}{R R-D}
$$

and from formulas (1) and (3) obtain

$$
G L E=G L \frac{S * R R}{R^{*} R R+R^{*} S+R R^{*} S}
$$

We wish to note that standard practice in the USGS short period networks for the last three decades has been to individually calibrate new seismometers, and then use formulas (5) and (6) to determine $S$ and $T$ values to produce a desired "standard" output. Damping was set to 0.80, and the damped generator constant (GLE) was set to $100 \mathrm{v} / \mathrm{m} / \mathrm{s}$ for $1 \mathrm{~Hz}$. L-4C seismometers, and $50 \mathrm{v} / \mathrm{m} / \mathrm{s}$ for $2 \mathrm{~Hz}$. L-22D's. The $T$ resistor was used to reduce the output level to a standard value, and this was of little consequence, given the very limited dynamic range of the analog telemetry (40-50 dB) which is still in use today.

Today, however, when modern digital recording systems are utilized, the dynamic range of the recording system may exceed that of the seismometer, and it might be worth reconsidering this strategy. In addition, all of the data is archived in formats that preserve system response parameters for each site, so it is not necessarily required that all seismometer set ups be identical. 
(It is more important that they be calibrated regularly.) Thus in cases where seismometers are individually calibrated, the shunt resistor could be determined as in Scenario III above, no series resistor included, and the seismometer output maximized into the recording unit.

In all of these cases, the corresponding "poles and zeros" can be found by assuming that the seismometer transfer function can be written:

$$
\frac{X(s)}{Y(s)}=\frac{s^{2}}{s^{2}+2 \beta \varpi_{0} s+\varpi_{0}^{2}},
$$

in which case the zero's are zero, and the poles are just the roots of the denominator. So from the quadratic equation, the real part of the roots is just $\beta \varpi_{0}$, and the imaginary parts are $\pm \varpi_{0} \sqrt{1-\beta^{2}}$.

\section{Scenario I}

\section{RESULTS}

Formulas (1) and (2) have been used to compute seismometer responses for all the sensors used in the SCVSE, which are tabulated in Table 1. All are moving coil velocity sensors, manufactured by Mark Products, and fall into three groups.

1. PASSCAL L-22D. These are set up with a $20 \mathrm{~K}$ Ohm shunt resistor $(S)$, and no series resistor (T). They have not been individually calibrated, so the values listed for $T_{0}, \beta$ and GLE of $0.5 \mathrm{~s}, 0.73$, and $88 \mathrm{v} / \mathrm{m} / \mathrm{s}$ are all nominal values, and should not be assumed accurate to better than $10-15 \%$. (Only one set of values is listed for these sensors, since only nominal calibration values are available.)

2. USGS L-22D. These have been individually calibrated, and $S$ and $T$ resistors installed to bring the outputs to "standard values" of $50 \mathrm{v} / \mathrm{m} / \mathrm{s}$ and 0.8 damping, when recorded on a system with $2 \mathrm{M}$ Ohm input impedance. The $T_{0}$ values have been individually measured as part of the calibration procedure. Were it not for the unknowns introduced by aging of the springs, and accumulated wear and tear from travel and use, these parameters should all be good to about $\pm 5 \%$. Since most of the calibrations were done 8 or 9 years ago, however (See Table 1), the uncertainties are likely comparable to those for the first group.

3. USGS L-4C. These sensors were all individually calibrated, and $S$ and $T$ resistors installed to bring the outputs to "standard values" of $100 \mathrm{v} / \mathrm{m} / \mathrm{s}$ and 0.8 damping, when recorded on a system with $10 \mathrm{~K}$ Ohms of input impedance, the "standard" for USGS short period analog networks. When recorded on a REFTEK recorder with an input impedance of 2M Ohms, the damping and motor constants differ considerably from the nominal values. Since the various resistances all enter non-linearly in formulas (1) and (2), the effect is not to simply multiply the outputs by constant factors, and thus GLE and $\beta$ must be computed individually for each component. Roughly speaking the effect has been to increase the output by 30-40\%, and reduce the damping to less than 0.7 (Table 1). All of these 
sensors were calibrated within the last 5 years, so it is likely that the computed values for GLE and $\beta$ are good to $\pm 5 \%$.

\section{Scenario II}

Three of the USGS L-22D seismometers from the second group were recalibrated after the 1998 SCVSE, and new $S$ and $T$ resistors installed. We applied formulas (5) and (6) to obtain values for the $S$ and $T$ resistors required to produce the desired output. These results are shown for two cases, one corresponding to a $10 \mathrm{~K}$ Ohm input impedance, the second a $2 \mathrm{M}$ Ohm input. It is clear from the results that many of these sensors cannot be used into a $10 \mathrm{~K}$ Ohm input, since a negative shunt resistance is required to produce the desired output.

When we compare the values of $G L$ and $\beta_{0}$ obtained for these three sets of sensors to those obtained seven years ago, we find that they have decreased on the average by 8 and 14\%, respectively, with standard deviations of the same order. It is unclear at this time whether this is the result of a change in the free period, sagging springs, or a change in the magnets. In any case, for these sensors, which have for the most part not been recalibrated in 8-9 years, assuming an uncertainty in the seismometer responses of $10-15 \%$ would seem in order.

\section{Scenario III}

The parameters for these same nine recalibrated seismometers are shown in Table 3, where formulas (7) and (8) have been used to determine the value of the shunt resistor $(S)$ that will produce 0.80 damping with $T=0$. This illustrates that when recorded on systems with high input impedance, the L22D seismometers can produce about $100 \mathrm{v} / \mathrm{m} / \mathrm{s}$ of output, when the series resistor $(T)$ is omitted. Also shown are the comparable parameters for recording into $10 \mathrm{~K}$ Ohms of input impedance; again the shunt resistances are negative, indicating that these sensors cannot achieve .80 damping on a low impedance system.

Shown at the bottom of Table 3 are calibration values for an older series of seismometers, the EV-17's, manufactured by Mandrel Industries in the 1960's. (The USGS still possesses about 15 sets of these $1 \mathrm{~Hz}$. sensors, and we intend to use them in an upcoming experiment in San Francisco.) Applying formulas (7) and (8), we see that the EV-17s, with a 500 Ohm coil resistance, require 1,386 Ohms to achieve a damping of .707, while those with 5000 Ohm coils require 12,696 Ohms. With these shunt resistances the outputs are 157 and $480 \mathrm{v} / \mathrm{m} / \mathrm{s}$, respectively, for the 500 and 5000 Ohm models.

Online copies of this report and accompanying tables can be obtained as Work and Excel documents at: http://geopubs.wr.usgs.gov/open-file/of99-434/. Information about the San Jose and Oakland / San Francisco urban seismic experiments can be found at: http://www.osfusa.com, (Oakland - San Francisco Urban Seismic Array) where it is also possible to volunteer to host a seismic station in the back yard of your home or business in Oakland or San Francisco. Copies of the data obtained in the 1998 San Jose experiment can be obtained through the PASSCAL Data Management System at: http://www.iris.washington.edu/PASSCAL/passcal.htm . (Look under experiment XL for the San Jose data.)

\section{ACKNOWLEDGMENTS}


We wish to thank John Coakley, Don Ritchey and Gonzalo Mendoza for helping with the calibration procedures and cables, Jack Van Schaack, Tom Burdette and Chris Dietel for help in tracking down and understanding the calibration documentation, and Jack Van Schaack, Richard Warrick and Shawn Dardenelle for reviewing the manuscript.

\section{REFERENCES}

Asten, M.W. (1977). Theory and Practice of Geophone Calibration In Situ Using a Modified Step Method, IEEE Trans. on Geoscience Elec., GE-15, pp. 208-214.

Bakun, W.H. and J. Dratler, Jr. (1976). Empirical Transfer Functions for Stations in the central California seismological Network. U.S. Geol. Surv. Open-File Report 76-259, 76 pages.

Eaton, J.P. (1975). Harmonic Magnification of the Complete Telemetered Seismic System, from Seismometer to Film Viewer Screen, U.S. Geol. Surv. Open-File Report 75-99, 40 pages.

Eaton, J.P. (1977). Frequency Response of the USGS Short Period Telemetered Seismic System and Its Suitability for Network Studies of Local Earthquakes. U.S. Geol. Surv. Open-File Report 77-844, 50 pages.

Eaton, J.P. (1991). Calibration of a Linear Spring-Supported, Vertical-Component, Moving-Coil Seismometer by means of Damping Tests and/or a Current Release Test. U.S. Geol. Surv. Open-File Report 91-635, 29 pages.

Healy, J.H. and M.E. O'Neill (1977). Calibration of Seismographic Systems: USGS Stations in the Central California Network. U.S. Geol. Surv. Open-File Report 77-736, 176 pages.

Lindh, A.G. and others (1999). The Santa Clara Valley Seismic Experiment: An Experiment in Urban Seismology. Unpublished manuscript.

Liu, H.P. and L. Peselnick (1986). Improved phase-ellipse method for in situ geophone calibration. Geophys. Prosp., 34, p. 537-544.

Rodgers, P.W., A.J. Martin, M.C. Robertson, M.M. Hsu, and David B. Harris (1995). SignalCoil Calibration of Electromagnetic Seismometers. Bull. Seis. Soc. Amer., 85, pp. 845850.

Stewart, S.W. and M.E. O'Neill (1980). Calculation of the Frequency Response of the USGS Telemetered Short-Period Seismic System. U.S. Geol. Surv. Open-File Report 80-143, 83 pages. 